Original Article

\title{
SCREENING OF SELECTED PLANT ESSENTIAL OILS FOR THEIR ANTIFUNGAL ACTIVITY AGAINST CANDIDA SPECIES ISOLATED FROM DENTURE STOM ATITIS PATIENTS
}

\author{
Vinaya Bhat ${ }^{1}$, S.M. Sharma ${ }^{2}$, Veena Shetty ${ }^{3}$, C.S. Shastry', Vaman Rao ${ }^{5}$, \\ Shilpa M. Shenoy ${ }^{6}$, Santanu Saha ${ }^{7} \&$ Sriram Balaji ${ }^{8}$
}

${ }^{1}$ PhD Research Scholar, ${ }^{8} \mathrm{PG}$ Student, Department of Prosthodontics, ${ }^{2} \mathrm{HOD}$, Professor \& PhD Guide, Department of Oral \& M axillofacial Surgery, A B Shetty M emorial Institute of Dental Sciences, ${ }^{3} \mathrm{Co}$-Guide, ${ }^{6} \mathrm{PhD}$ Research Scholar, Department of M icrobiology, K. S. Hegde M edical Academy, ${ }^{4}$ Principal \& Co-Guide, NGSM Institute of Pharmaceutical Sciences, ${ }^{7}$ Senior Lecturer, Department of Pharmacognosy, NGSM Institute of Pharmaceutical Sciences, Nitte University, M angalore, ${ }^{5} \mathrm{Co}$-Guide, Department of Biosciences, NM AM Institute of Technology, Nitte, M angalore, INDIA.

\author{
Correspondence \\ Vinaya Bhat \\ PhD Research Scholar, Department of Prosthodontics, A B Shetty M emorial Institute of Dental Sciences, Nitte University
} Deralakatte, Mangalore - 575 018, Karnataka, India.

Mobile: +91 9481921180 E-mail : drvinayabhat@gmail.com

\begin{abstract}
Background: M any efforts have been made to discover new antimicrobial compounds from various sources such as micro-organisms, animals and plants. Use of herbal medicines has a long history in Asian population in treating different ailments. Many plants have been found to have properties like antibacterial, antifungal and antioxidant activities.

In a complete denture wearer, due to either local or systemic factors, denture stomatitis has been found to a have high prevalence. In such patients, higher incidence of Candida infection and increased levels of Candida spp. also have been identified. Existing antifungal agents like Nystatin \& Fluconazole have been found to have toxic effects on long term application and chances of development of drug resistance is high. M edicinal plants have been used to inhibit growth and development of fungal infection from Candida isolated from sites other than oral cavity.
\end{abstract}

Objectives: To evaluate the antifungal activity of some of the medicinal essential oils against oral isolates of Candida obtained from denture wearing patientsidentified through a survey.

Materials and Methods: The oral isolates of Candida species were collected after conducting a survey of complete denture wearers, wearing the denture for at least more than a year. The speciation of the organism was done after identifying it from the specimens. It was confirmed with the help of germ tube test, other biochemical tests and chlamydospore formation tests. A lab isolate also was included in the study. The essential oils of different herbs were extracted using hydro distillation methods. The antifungal activity of these oils was tested and compared with antifungal activity of Nystatin and fluconazole using modified Kirby-Baeur method. The inhibition zones of different oils were measured and compared among themselves against all the clinical isolates and the lab isolate.

Results: About 55 complete denture wearing patients have been surveyed and among them 27 have been found to be positive for Candida-associated denture stomatitis. Among the Candida species, Candida albicans was more prevalent followed by $\mathrm{C}$. tropicalis and C. glabrata.

Among the test essential oils, Origanum vulgare (stored \& fresh) and clove oil gave positive results against all isolates. The fresh samples gave better results than the stored and all three oils showed more antifungal activity than Nystatin \&

Access this article online

Quick Response Code

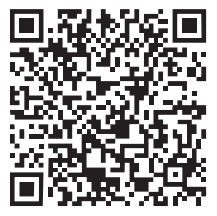

fluconazole.

Interpretation: The candida-associated denture stomatitis is prevalent in patients who are wearing denture prosthesisfor more than a year.

Candida albicans is the most prevalent causative species followed by C. tropicalis and C. glabrata.

Origanum vulgare and clove oil are potent antifungal agents against oral species of Candida. They can be either used separately or their synergistic activity could be explored against denture stomatitis.

Key words: Denture stomatitis, herbal essential oils, clove oil, origanum vulgare, Candida spp., nystatin, fluconazole 


\section{Introduction}

High prevalence of denture stomatitis has been observed in patients who are wearing complete denture prosthesis. About 60 to $70 \%$ of prevalence has been reported by various authors in the past ${ }^{1-6}$. In geriatric patients, when there is immune suppression due to any reason, there is a conversion of the normal oral commensal Candida into an infection causing pathogen ${ }^{7-15}$. The pathogenic fungi Candida grow in large numbers forming biofilms on the surface of the prosthesis and on the oral mucosa. These biofilms have been found to be highly resistant to existing antifungal agents like Nystatin and Fluconazole. M oreover, these drugs when administered on a long term basis have been known to cause toxicity in human beings.

Efforts are being made to discover new antifungal agents from sources like micro organisms, animals and plants, which are either less toxic or not toxic at all. Use of plant extracts has a long history in Indian scenario for treatment of different ailments. Plants have been found to have rich source of antibacterial, antioxidant and antifungal activities. Several studies using plant essential oils have been carried out against Candida isolated from areas other than oral cavity ${ }^{16-20}$. No studies are reported in the literature regarding their effect against oral species of Candida in a denture wearer. Hence this study was undertaken with the aim of evaluating the effect of eight different plant essential oils on oral isolates of Candida retrieved from a denture wearing patients. Conventional antifungal agents like Nystatin and Fluconazole were also added as controls. A lab isolate was taken for comparative purposes and Agar Well diffusion method was implemented to study the susceptibility tests.

\section{Materialsand Methodology:}

Ethical clearance for the present study was obtained from the ethical committee of NITTE University, Mangalore, Karnataka, India. The clinical isolates of Candida required for the study were collected through a survey conducted in the department of Prosthodontics. Fifty five patients wearing complete denture prosthesis for more than a year were selected based on the selection criteria.

\section{Selection criteria:}

\section{Inclusion Criteria:}

1. Patients wearing a denture $>1$ year

2. Patients not on any antifungal agent

3. Patients willing to participate in the study

\section{Exclusion criteria:}

1. Patients unwilling to participate in the study

2. Patients wearing a denture for $<1$ year

3. Patientsalready on antifungal therapy

A structured questionnaire was prepared to obtain the necessary information from the patients. Once selected, they were explained about the study and a written consent was obtained. About 27 patients were found to be positive for denture stomatitis observed through clinical signs and symptoms.

Collection of Candida samples: The isolates were collected from saliva samples of the selected patients. The patient was made to sit comfortably on the dental chair. The maxillary denture was removed and using a sterile cotton bud sample was collected from the palatal aspect of the tissue surface of the denture. (Fig.01). It was immediately placed in a test tube containing Phosphate Buffer Solution and was transported to the laboratory where it was cultured on the Saboraud's Dextrose Agar (SDA) to separate the Candida.

\section{Isolation of different species:}

Once the Candida was identified, it was once again incubated in SDA medium at $37 \mathrm{C}$ for 48 hours. Candida was confirmed using Germ Tube Test, Biochemical assays and CHROMagar tests (Fig. 02). Based on color of the colonies in CHROMagar, species in the samples were identified as C. albicans (pale green, 13/27), C. tropicalis (09/27), and C. glabrata (05/27). Once isolated, they were separated and subcultured for further use.

A lab isolate ATCC90028 of C. albicans was added in the study for comparative purposes.

\section{Collection of plant material:}

The dry leaves of Origanum vulgare were purchased from JKH Impex Pvt. Ltd. Mumbai. Leaves of Pogostemon 
patchouli, Oscimum sanctum and Neem were collected locally and the leaves were identified taxonomically at the University of Agricultual Sciences, Bengaluru. Commercially available Origanum vulgare, clove and caprylate were purchased from departmental store.

\section{Preparation of herbal essential oils:}

The fresh leaves of Pogostemon patchouli, Oscimum sanctum and Neem were dried at room temperature and were powdered. Essential oils from all plants were extracted using hydrodistillation procedure and the oils were stored at $-4^{\circ} \mathrm{C}$ till use. Nystatin and fluconazole were added as controls.

Antifungal susceptibility testing (Well diffusion method): A modified Kirby-Beur method was used. Here, the

Table 1 : Antifungal activity of the essential oils of the collected plants

\begin{tabular}{|c|c|c|c|c|c|}
\hline Plant name & Botanical name & \multicolumn{3}{|c|}{ Zone of inhibition $(\mathrm{mm} / 20 \mu \mathrm{l})$} & \\
\hline & & $\begin{array}{l}\text { Candida } \\
\text { albicans }\end{array}$ & $\begin{array}{l}\text { Candida } \\
\text { glabrata }\end{array}$ & $\begin{array}{l}\text { Candida } \\
\text { tropicalis }\end{array}$ & $\begin{array}{c}\text { Candida albicans } \\
\text { (Lab isolate ATCC90028) }\end{array}$ \\
\hline $\begin{array}{l}\text { Origanum (stored } \\
\text { extract) }\end{array}$ & $\begin{array}{l}\text { Origanum } \\
\text { vulgare }\end{array}$ & $30 \pm 5$ & $35 \pm 2$ & $30 \pm 2$ & $30 \pm 4$ \\
\hline $\begin{array}{l}\text { Origanum (fresh } \\
\text { extract) }\end{array}$ & $\begin{array}{l}\text { Origanum } \\
\text { vulgare }\end{array}$ & $30 \pm 3$ & $36 \pm 2$ & $32 \pm 3$ & $30 \pm 2$ \\
\hline $\begin{array}{l}\text { Origanum } \\
\text { (commercial) }\end{array}$ & $\begin{array}{l}\text { Origanum } \\
\text { vulgare }\end{array}$ & --- & ---- & --- & ---- \\
\hline $\begin{array}{l}\text { Patche Kadiru } \\
\text { (Kannada) }\end{array}$ & $\begin{array}{l}\text { Pogostemon } \\
\text { Patchouli }\end{array}$ & --- & ---- & --- & --- \\
\hline Tulasi & $\begin{array}{l}\text { Oscimum } \\
\text { Sanctum }\end{array}$ & ---- & ---- & ---- & ---- \\
\hline Clove & $\begin{array}{l}\text { Syzygium } \\
\text { aromaticum }\end{array}$ & $33 \pm 4$ & $30 \pm 2$ & $30 \pm 2$ & $33 \pm 1$ \\
\hline Neem & $\begin{array}{l}\text { Azadirachta } \\
\text { indica L }\end{array}$ & ---- & ---- & ---- & ---- \\
\hline Coconut & $\begin{array}{l}\text { Cocosnicifera } \\
\text { Sanctum }\end{array}$ & ---- & ---- & ---- & ---- \\
\hline
\end{tabular}

Table II : Descriptive analysis of data

Comparison of three essential oils in each group

\begin{tabular}{|c|c|c|c|c|c|c|c|c|}
\hline & & $\mathrm{N}$ & Mean & $\begin{array}{c}\text { std. } \\
\text { Deviation }\end{array}$ & $\begin{array}{l}\text { df } \\
\text { Squ }\end{array}$ & $\begin{array}{l}\text { Mean } \\
\text { re }\end{array}$ & $\mathrm{F}$ & Sig. \\
\hline \multirow[t]{4}{*}{ candida albicans } & origanum vulgare (o $p$ ) stored at 4 & 10 & 29.9 & 3.281 & 2 & 9.733 & 1.547 & 0.23 \\
\hline & origanum vulgare fresh extract & 10 & 30.1 & 2.025 & & & & \\
\hline & clove oil & 10 & 31.7 & 2.003 & & & & \\
\hline & Total & 30 & 30.57 & 2.555 & & & & \\
\hline \multirow[t]{4}{*}{ candida glabrata } & origanum vulgare (o $p$ ) stored at 4 & 10 & 35 & 1.491 & 2 & 103.333 & 35.769 & $\leq 0.00$ \\
\hline & origanum vulgare fresh extract & 10 & 36 & 2.055 & & & & \\
\hline & clove oil & 10 & 30 & 1.491 & & & & \\
\hline & Total & 30 & 33.67 & 3.133 & & & & \\
\hline \multirow[t]{4}{*}{ candida tropicalis } & origanum vulgare (o p) stored at 4 & 10 & 30 & 1.491 & 2 & 14.033 & 4.802 & $\underline{0.01}$ \\
\hline & origanum vulgare fresh extract & 10 & 32 & 2.16 & & & & \\
\hline & clove oil & 10 & 29.9 & 1.37 & & & & \\
\hline & Total & 30 & 30.63 & 1.921 & & & & \\
\hline \multirow{4}{*}{$\begin{array}{l}\text { candida albicans } \\
\text { lab isolate (control) } \\
\text { (ATCC90028) }\end{array}$} & origanum vulgare (o p) stored at 4 & 10 & 29.9 & 2.644 & 2 & 29.233 & 8.919 & $\underline{0.00}$ \\
\hline & origanum vulgare fresh extract & 10 & 30.2 & 1.476 & & & & \\
\hline & clove oil & 10 & 33 & 0.816 & & & & \\
\hline & Total & 30 & 31.03 & 20251 & & & & \\
\hline
\end{tabular}

There is significant difference in the candida glabrata, tropicalis and lab isolate 
Candida species were suspended in SDA broth and it was made equivalent to $0.5 \mathrm{M}$ cFarland units. Six millimeter wells were created on the SDA medium and 20 microlitre each of the antifungal agents was delivered into each well. It was incubated again for further 48 hours at $37^{\circ} \mathrm{C}$ with agitation. After 48 hours, zone of inhibition for each essential oil and for each species was measured using a flexible scale (Fig.03). The results were tabulated (Table I) and were subjected to statistical analysis.

\section{Results:}

Among eight essential oils (Origanum vulgare in three forms, i.e., fresh extract, stored extract \& commercial, Pogostemon patchouli, Oscimum sanctum, Neem, clove and caprylate) three showed positive effects against Candida species. Origanum vulgare in two forms, i.e. Fresh extract, and stored extract and Clove oil showed significant results $(p \varangle 0.001$ ) on all species of Candida. All showed more antifungal effect than Nystatin $(22 \mathrm{~mm}$ zone of inhibition) and fluconazole (19mm zone of inhibition). Among fresh and preserved forms of Origanum vulgare, fresh samples showed better results $(30 \pm 3,36 \pm 2,32 \pm 3$, $30 \pm 2$ ) against all species. There was no significant difference $(P \varangle 0.231$ ) in action of three oils on Candida albicans where as there was significant difference in Candida glabrata, C. tropicalis and lab isolate $(\mathrm{P} \varangle 0.001$, $0.016,0.001$ ). This indicates that all three oils have similar activity against Candida albicans and the action is different for other three species. C. glabrata and C. tropicalis are more susceptible to Origanum vulgare rather than clove oil, where as lab isolate is more susceptible to clove oil. Hence any of the three oils can be used effectively against oral Candida albicans and Origanum vulgare is also effective on other oral isolates. Clove oil is more effective on lab isolate of Candida albicans ATCC90028. Origanum vulgare also showed significant difference as compared to Fluconazole $\&$ Nystatin $(\mathrm{P} \varangle$.001) (Table II) \& (Table III).

\section{Discussion :}

Denture stomatitis is a very common type of infection of the oral mucosa found in 60 to $65 \%$ of the denture wearing population ${ }^{21,22}$. Various reasons have been cited by the authors for this prevalence. Denture hygiene, trauma and allergy to the denture base materials are the commonest causes. In addition, when the immune status of the patient is lowered due to systemic diseases or due to immunosuppressive therapy, the otherwise normal oral commensal Candida turns pathogenic and causes denture stomatitis. Histologic sections of the oral mucosa have been shown to exhibit Candida blastospores, hyphae and pseudohyphae.

In diabetes mellitus, the patients have been found to be more susceptible to oral candidiasis than patients without diabetes ${ }^{23-24}$. If the patient is a denture wearer, it has been found to favor the growth of candida to cause candidiasis ${ }^{24}$ ${ }^{25}$. In a study by Sanita et $\mathrm{al}^{6}$, they said that Candida species were more prevalent in patients with denture stomatitis in both, diabetic and non diabetic conditions. Diabetes mellitus has been a risk factor for the development of DS. In a study by Emami et $\mathrm{al}^{5}$, they found that the patient who is wearing a removable denture whether partial or complete is at a risk of developing DS. Presence of dental prostheses has also been found to be associated with HIV/AIDS ${ }^{15}$. They are of the opinion that CD4 count plays an important role in the development of oral candidiasis.

Candida albicans has been found to be the most prevalent species in Candida-related denture stomatitis. Under normal circumstances, it is a common oral commensal not causing any pathosis. However, during favourable conditions it transforms itself into a virulent pathogen using various mechanisms.

Even though Candida albicans is the frequently associated species in denture stomatitis, $\mathrm{C}$. glabrata is the emerging species next to it ${ }^{26-29}$. However, Sanita et $\mathrm{al}^{6}$, in their study concluded that $\mathrm{C}$. albicans and $\mathrm{C}$. tropicalis were more prevalent in a denture wearer with denture stomatitis. In severe candidiasis, C. tropicalis was more prevalent. Mixed infections caused by $\mathrm{C}$. albicans and C. glabrata have been demonstrated in vitro oral epithelium ${ }^{30}$. Reconstructed Human Oral epithelium was used to demonstrate the ability of $C$. albicans to enhance the invasiveness of $C$. glabrata in causing the infection. 
To arrive at a conclusion regarding the dominance of the species in the local population the authors conducted a survey to include denture wearers from where the samples were collected for species characterization of Candida. In this survey, we found that after C. albicans, it was C. tropicalis and then $\mathrm{C}$. glabrata which were the next most prevalent species of Candida.

Existing antifungal agents like Nystatin and Fluconazole have been found to be toxic on long term use ${ }^{31-35}$. Also, development of resistance by the organisms has been recorded. ${ }^{\circledR}$ Hence, there is a need to develop a new antifungal agent which may be less or not toxic at all. Plants have a long positive history for being used as natural remedies for various ailments ${ }^{36-38,18}$. Several herbal agents have been tried against Candida of various regions in the human body ${ }^{18-20}$. However, no studies have been reported regarding the investigation of antifungal effects of any herbs on the Candida strains obtained from the oral candidiasis of a denture wearing patient. This study was undertaken to screen some of the herbal products that are commonly available against Candida spp. of oral candidiasis.

A modified Kirby-Beur method was implemented to study the antifungal susceptibility potential of the eight herbs. Zone of inhibition for each was measured and tabulated. Three oils (two types of Origanum vulgare and clove oil) showed strong positive antifungal effects on all strains (Clinical and lab) of Candida, where as, the other oils did not show any measurable activity at all. Zone of inhibition for stored Origanum vulgare was $30 \mathrm{~mm} \pm 5$ for Candida albicans, $30 \mathrm{~mm} \pm 2$ for Candida tropicalis, $35 \mathrm{~mm} \pm 2$ for Candida glabrata and $30 \mathrm{~mm} \pm 4$ for Candida lab isolate. For fresh sample of Origanum vulgare was, $30 \mathrm{~mm} \pm 3$ for $C$. albicans, $32 \mathrm{~mm} \pm 3$ for $\mathrm{C}$. tropicalis, $36 \mathrm{~mm} \pm 2$ for $\mathrm{C}$. glabrata and $30 \mathrm{~mm} \pm 2$ for the lab isolate. Clove oil exhibited $33 \mathrm{~mm} \pm 4 \mathrm{~mm}$ for $\mathrm{C}$. albicans, $30 \mathrm{~mm} \pm 2 \mathrm{~mm}$ for $\mathrm{C}$. tropicalis, $30 \mathrm{~mm} \pm 2 \mathrm{~mm}$ for c. glabrata and $33 \mathrm{~mm} \pm 1 \mathrm{~mm}$ for lab isolate. Nystatin has been found to show an antifungal effect of up to $22 \mathrm{~mm}{ }^{18}$ and fluconazole upto $19 \mathrm{~mm}{ }^{39}$. In this study, the antifungal effects of Origanum vulgare and clove oil were found to be substantially high as compared to Nystatin and Fluconazole, indicating that they can have better results in eradicating candidiasis. And being of plant origin, they may be less toxic. Further studies on the toxic effects of these oils on animals are indicated.

Origanum vulgare is a plant belonging to the family Lamiaceae which contains the phenolic compound Carvacrol as a primary compound ${ }^{40}$. In a few earlier studies, the essential oil of Origanum vulgare has been studied against Candida spp. isolated from sites such as, vaginal mucous membrane of dogs, cutaneous tegument of a dog, cutaneous tegument of a capuchin monkey ${ }^{20}$, culture collection Candida albicans ATCC10231 ${ }^{38}$, ATCC $14053^{18}$, female mice ${ }^{19}$ and from human stool specimen ${ }^{18}$. In all the above studies Origanum vulgare has been found to be possessing anti-candidal activity. In the present study, the Candida spp. was obtained from the oral cavity and this plant was found to be very effective against different species of Candida and so also a lab species of Candida albicans. Both, the stored and the fresh extracts showed good antifungal effect as compared to fluconazole and nystatin, indicating that proper storage does not decrease the potency of the oil.

Syzygium aromaticum (clove) had been used against lab isolate of Candida albicans ATCC 10231 by Hammer et al. ${ }^{38}$. In their study of antimicrobial activity of essential oils and plant extracts carried on several organisms they found that clove had an antifungal effect against Candida albicans. In our study also, the essential oil of clove showed a strong antifungal activity against several species of Candida obtained from the oral cavity thus confirming its possession of positive antifungal effects.

\section{Conclusion:}

This study has scientifically proved the antifungal efficacy of three essential oils obtained from fresh $\&$ stored samples of Origanum vulgare and Clove oil. Further, it was found that the effects are much more than the existing antifungals like Nystatin \& Fluconazole. The usage of Origanum vulgare or clove oil or the combination of the two essential oils has the potential of being used in treating 
oral candidiasis. The present in-vitro study has confirmed the potentiality of the two essential oils to be used as antifungal agents against Candida spp. However, further studies to determine their MIC\& M FC and also the phase II

\section{References}

1. Kebe K, Morii K, Matsuda Kk, Hata K, Nokubi T. Journal of Oral Rehabilitation 2006;33:36-42.

2. Liu X, Hua H. Oral Manifestation of Chronic Mucocutaneous Candidiasis: Seven Case Reports. J oral Pathol M ed 2007;36:528-32.

3. Pereira-cenci T, Del bel cury AA, Crielaard W, Ten cate JM. Development of Candida-associated Denture Stomatitis: New Insights. J Appl Oral Sci. 2008;16:86-945.

4. Williams D, Lewis M. Pathogenesis and treatment of oral candidosis. Journal of Oral M icrobiology 2011:3.

5. Emami E, Taraf H, Grandmont P, Gauthier G, Koninck L, Lamarche C, de.Souza R. The association of Denture Stomatitis and Partial Removable dental Prostheses: A Systematic Review. Int J Prosthodont 2012;25:113-9.

6. Sanita PV, Pavarina AC, Eunice TG, Silva M M, M ima EGO, Ribeiro DG, Vergani CE. Candida spp. prevalence in well controlled type 2 diabetic patients with denture stomatitis. Oral Surg Oral Med Oral Pathol Oral Radiol Endod 2011;111:726-33

7. Dangi YS, Soni M L, Namdeo KP. Oral Candidiasis: A Review. International Journal of Pharmacy and Pharmaceutical Sciences; 2010; 2(4).

8. Dongari-Bagtzoglou A et al. Oral Candida Infection and Colonization in Solid Organ Transplant Recipients. Oral Microbiol Immunol 2009;24:249-54.

9. Olczak-Kowalczyk D et al. Oral Candidiasis in Immunosuppressed Children and Young Adults after Liver or Kidney Transplantation. Pediatric Dent 2010;32:189-94.

10. Reichart PA, Samaranayake LP, Bendick Ch, Schmidt-Westhausen M, Jayalathike MS. Prevalence of Oral Candida Species in Leprosy Patients from Cambodia and Thailand. J Oral Pathol Med 2007;36:342-6.

11. Samaranayake, LP et al. Fungal Infections associated with HIV Infection. Oral Diseases. 2002;2:151-60.

12. Sashikumar R, Kannan R. Salivary Glucose Levels and Oral Candidal Carriage in Type II Diabetics. Oral Surg Oral Med Oral Pathol Oral Radiol Endod 2010;109:706-711.

13. Scully C,El-Kabir M, Samaranayake LP. Candida and Oral Candidosis: A Review. Critical Reviews in Oral Biology and M edicine,1994;5:125-157.

14. Thompson GR et al. Oropharyngeal candidiasis in the era of antiretroviral therapy. Oral Surg Oral Med Oral Pathol Oral Radiol endod 2010;109:488-95.

15. Witzel AL, Pires M FC, Carli M L, Rabelo GD, Nunes TB. Candida albicans isolation from Buccal M ucosa of Patients with HIV wearing removable dental prostheses. Int J Prosthodont 2012;25:127-131.

16. Javidnia K, M iri R, Assadollahi M, Gholami M, Ghaderi M. Screening of selected plants growing in Iran for antimicrobial activity. Iranian Journal of Science \& Technology, Transaction A.2009;33:329-333

17. Rosato A, Vitali C, Piarulli M, M azzotta M, Argentieri MP, Rosanna M. In vitro efficacy of the combination of Nystatin with the essential oils of Origanum vulgare and Pelargonium graveolens against some Candida species. International Journal of Phytotherapy \& amp:Phytopharamacology. 2009; Elsevier.

18. Stiles JC, Sparks W, Ronzio RA. The Inhibition of Candida albicans by Oregano. J of Applied Nutrition 1995;47:4:1-7.

19. M anohar V, Ingram C, Gray J, Talpur NA, Echard BW, Bagchi D et al. Antifungal Activities of Origanum oil against Candida albicans. Molecular and Cellular Biochemistry. 2001;228:111-117.

20. Cleff MB, M einerz AR, Xavier M, Schuch LF, M eireles MCA, Rodrigues $M$ RA et al. In Vitro activity of Origanum vulgare essential oil against Candida species. Braz. J. M icrobiol. 2010;41(1).

21. Webb BC, Thomas CJ, Willcox MD, Harty DW, Knox KW. Candidaassociated denture stomatitis. Aetiology and management: a review. studies on animals have to be carried out. Also, their pharmacological effects like antibacterial, anti carcinogenic and anti-inflammatory activities can be investigated.

Part 2. Oral diseases caused by Candida species. Aust Dent J. 1998;43:160-6.

22. Salerno C, Pascale M, Contaldo M, Esposito V, Busciolano, Milillo L, Guida A, Petruzzi M, Serpico R. Candida-associated denture stomatitis. Oral M ed and Pathol. 2010.

23. Belazi M, Velegraki A, Fleva A, Gidarakou I, Papanaum L, Baka D, et al. Candidal overgrowth in diabetic patients: Potential predisposing factors. Mycoses 2005;48:192-6.

24. Khosravi AR, Yarahmadi S, Baiat M, Shokri H, Pourkabireh M. Factors affecting the prevalence of yeasts in the oral cavity of patients with diabetes mellitus.J M ycol Med 2008;18:83-8.

25. Goncalves RH, M iranda ET, Zaia JE, Giannini MJ. Species diversity of yeast in oral colonization of insulin-treated diabetes mellitus patients. Mycopathologia 2006:162:83-9,

26. Li L, Redding S, Dongari-Bagtzoglou AD. Candida glabrata, an emerging oral opportunistic pathogen. J Dent Res 2007;86:204-15.

27. Redding SW, Kirkpatrick WR, Dib O, Fothergill AW, Rinaldi MG, Patterson T. The epidemiology of non-albicans Candida in oropharyngeal candidiasis in, HIV patients. Spec Care Dentist 2000;20:178-81.

28. Redding SW, Kirkpatrick WR, Coco BJ, et al. Candida glabrata oropharyngeal candidiasis in patients receiving radiation treatment for head and neck cancer. J Clin M icrobiol 2002:40:1879-81.

29. Coco BJ, Bagg J, Cross LJ, Jose A, Cross J, Ramage G. Mixed Candida albicans and Candida glabrata populations associated with pathogenesis of denture stomatitis. Oral Microbiol Immunol 2008;23:377-83

30. Silva S, Henriques M. Hayes A, Oliveira R, Azeredo J, Williams DW. Candida glabrata and Candida albicans co-infection of an in vitro oral epithelium. J Oral Pathol M ed. 2011;40:421-27

31. Charlier $\mathrm{C}$ et al. Fluconazole for the management of invasive candidiasis: where do we stand after 15 years?.J of Antimicrobial Chemotherapy, 2006;57:384-410.

32. Jafari-nodoushan AA, Kazemi A, Mirzaii F, Dehghani M. Fluconazole Susceptibility Profile of Candida isolates Recovered from Patients Specimens Admitted to yard Central Laboratory. Iranian J of Pharmaceutical Research 2008,7:69-75.

33. M artin M V. The Use of Fluconazole and Itraconazole in the Treatment of Candida albicans Infections: a Review. I of Antimicrobial Chemotherapy 1999;44:429-37.

34. Sheehan DJ, Hitchcock CA, Sibley CM. Current and Emerging Azole Antifungal Agents. Clin Microbiol Rev 1999;12:40-79.

35. Wu T, Wright K, Hurst SF, Morrison Cl. Enhanced extracellular Production of Aspartyl Proteinase, a virulence factor, by C. albicans isolates following growth in subinhibitory concentrations of fluconazole. Antimicrobial Agents and Chemotherapy. 2000;44:1200-1208.

36. Malabadi RB, Kumar SV. Assessment of Antifungal Activity of Some Medicinal Plants. Intl.J of Pharmacology.2007;3:499-504.

37. Meena AK et al. Review on antifungal activities of Ayurvedic Medicinal Plants. Drug Invention Today. 2009;2:146-48.

38. Hammer KA, Carson CF, Riley TV. Antimicrobial activity of essential oils and other plant extracts. Journal of Applied Microbiology 1999;86:985-990.

39. Pfaller MA, Barry AL. Evaluation of a Novel Colorimetric Broth Micro dilution M ethod for Antifungal Susceptibility Testing of Yeast Isolates. J of Clinical Microbiology, Aug.1994;32:1992-96.

40. Taxon: Origanum vulgare L. GRIN Taxonomy for Plants. United States Dept. of Agriculture. 